\title{
Vocal cord cavernous hemangioma - Case report
}

\author{
Tengchin Wang ${ }^{1 *}$ and Chiehjen $\mathrm{Wu}^{2}$ \\ ${ }^{1}$ Department of otolaryngology, Tainan municipal hospital (managed by show chwan medical care corporation), Tainan City, Taiwan \\ ${ }^{2}$ Department of pathology, Tainan municipal hospital (managed by show chwan medical care corporation), Tainan City, Taiwan
}

\begin{abstract}
\section{Introduction}

Hemangiomas of the larynx are generally classified into adult and infantile forms. Adult hemangiomas are rare and can be seen in different locations. They are more often of cavernous form and cause hoarseness [1]. In this report we present a patient with cavernous hemangioma of the right vocal cord.
\end{abstract}

Laryngeal hemangioma in adults is a very rare condition that occur commonly in the supraglottic regions of the larynx. We present on a heavy smoker man with husky voice for many years. Fiberscopic examination revealed a granular lesion on the right vocal fold. Laryngomicroscopic surgery is applied. Histological diagnosis is cavernous hemangioma with squamous hyperplasia. Laryngeal cavernous hemangioma isolated to the free edge of the vocal fold is a very rare clinical finding.

\section{Case}

A 59-year-old man complained of having husky voice for many years. He has history of bilateral nasal polyposis under treatment. By the way, he is also a smoker and alcohol use. On physical examination, a reddish bulging mass was seen on the right vocal cord anterior one third portion (Figure1).

Laryngomicroscopic surgery was applied to excise the lesion. During dissection, we found the lesion was pliable, originated from vocal fold edge and just encountered a few bleedings.

Histopathological findings revealed varying sized vascular spaces lined by flattened endothelial cells. Foci of fibrosis are seen. The

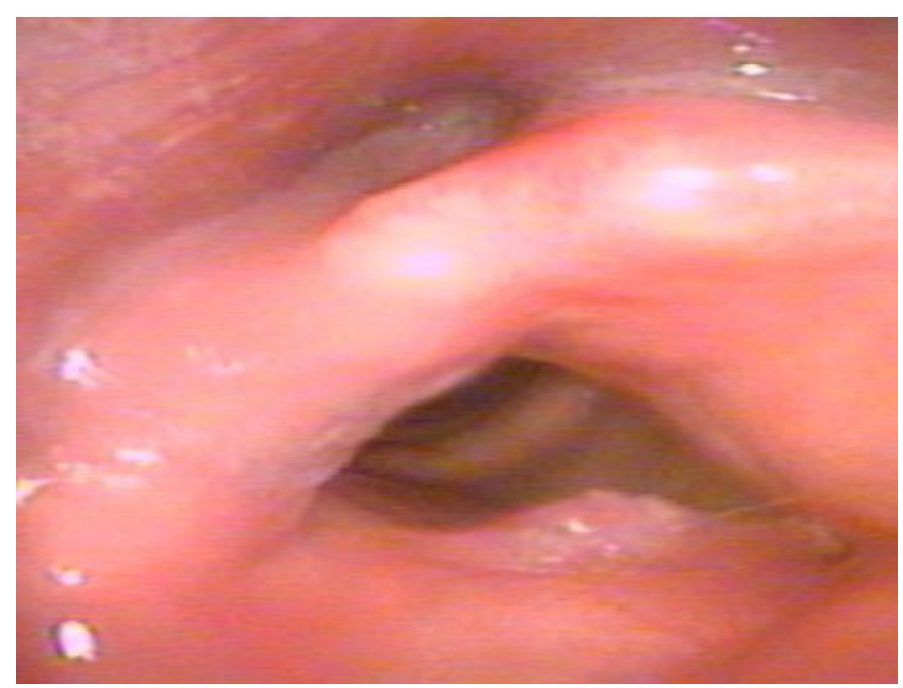

Figure 1. A redish bulging mass was seen on the right vocal cord anterior one third portion. overlying mucosa shows squamous hyperplasia, with koilocyte-like cells in the superficial layer (Figure $2 \mathrm{a}, \mathrm{b}$ ). The aforementioned features confirmed the diagnosis of cavernous hemangioma. The patient had an improvement of voice after two months of speech therapy.

\section{Discussion}

Laryngeal hemangioma in adults is a very rare condition that is generally seen in men. The causative factors are thought to be vocal abuse, cigarette smoking and laryngeal trauma (i.e., intubation) [1]. Adult hemangiomas occur at or above the level of the true cord, most of these lesions being usually cavernous hemangiomas. Though the occurrences of supraglottic hemangiomas are relatively common in adults, the occurrences of vocal fold hemangiomas are very rare, only few vocal cord hemangiomas have been described [2]. They have irregular surfaces that appear bluish in color [3]. The phonation sign of Menzel, which consists of increased firmness, erection, and deepening color of the growth during phonation, may be of diagnostic value [1] The principal symptom is hoarseness, occasional hemoptysis, and in advanced cases dysphagia and difficult breathing [4]. No active treatment is advised for adult laryngeal hemangiomas unless the lesions are symptomatic or show a tendency to involve other parts. There is no well-established treatment protocol for laryngeal hemangiomas. The various modalities of therapy depend upon the age of the patient, the site and size of the lesion, and the hemodynamic flow of the hemangioma. In conclusion, hemangiomas can be seen on vocal cords although they are very rare, and they generally cause problems in the voice of the patients. Excision of the lesion with microlaryngoscopic techniques gives satisfactory results in smaller lesions.

Correspondence to: Tengchin Wang, Department of otolaryngology, Tainan municipal hospital (managed by show chwan medical care corporation), No.670, Chongde Rd., East Dist., Tainan City 701, Taiwan. Tel: +886-6-2609926; E-mail: tengchin27@hotmail.com

Key words: cavernous hemangioma

Received: September 30, 2017; Accepted: October 24, 2017; Published: October 27,2017 


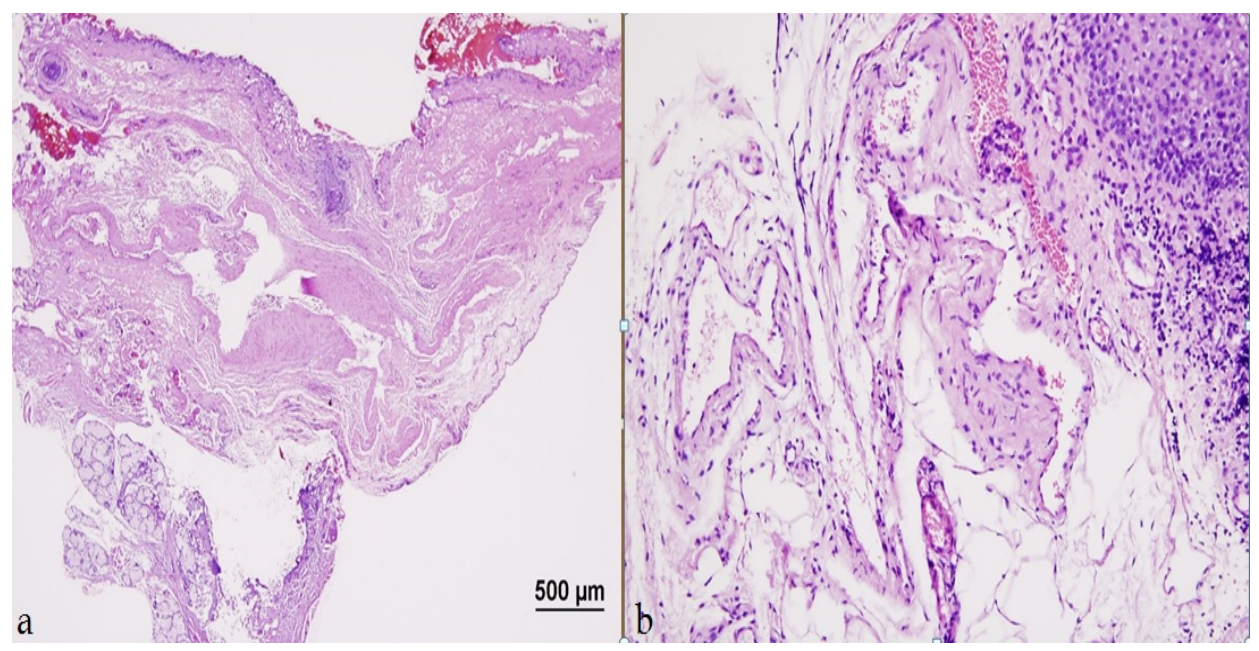

Figure 2. (a) feature of cavernous hemangioma, with focal fibrosis (hematoxylin-eosin stain, $\times 40$ ). (b) . cavernous hemangioma, formed by varying sized vascular spaces lined by flattened endothelial cells. (hematoxylin-eosin stain, $\times 400$ )

\section{References}

1. Kimmelman CP, Sugar JO, Lowry LD (1979) Resident's page. Pathologic quiz case 2. Hemangioma of the vocal cord. Arch Otolaryngol 105: 500-502

2. Prasad SC, Prasad KC, Bhat J (2008) Vocal cord hemangioma. Med J Malaysia 63: $419-420$ [Crossref]
3. Bastian WR (1993) Benign saccular and mucosal disorders; benign laryngeal tumors. In: Cummings WC (ed) Otolaryngology and head and neck surgery. Mosby Yearbook, St Louis, pp 1897-1923

4. Kiho L, Byard RW (2015) Acute fatal upper airway obstruction from an occult cavernous hemangioma of the larynxJ. Forensic Sci Jan;60 Suppl 1: S93-6 [Crossref]

Copyright: (C2017 Wang T. This is an open-access article distributed under the terms of the Creative Commons Attribution License, which permits unrestricted use, distribution, and reproduction in any medium, provided the original author and source are credited. 